\title{
Long-term outcome of infective endocarditis: A study on patients surviving over one year after the initial episode treated in a Finnish teaching hospital during $\mathbf{2 5}$ years
}

Maija Heiro' ${ }^{1}$ Hans Helenius ${ }^{2}$, Saija Hurme ${ }^{2}$, Timo Savunen ${ }^{3}$, Kaj Metsärinne ${ }^{1}$, Erik Engblom ${ }^{1}$, Jukka Nikoskelainen ${ }^{1}$ and Pirkko Kotilainen*1

Address: ${ }^{1}$ Department of Medicine, Turku University Hospital, Turku, Finland, ${ }^{2}$ Department of Biostatistics, University of Turku, Turku, Finland and ${ }^{3}$ Department of Surgery, Turku University Hospital, Turku, Finland

Email: Maija Heiro - maija.heiro@tyks.fi; Hans Helenius - hans.helenius@utu.fi; Saija Hurme - saija.hurme@utu.fi;

Timo Savunen - timo.savunen@tyks.fi; Kaj Metsärinne - kaj.metsarinne@utu.fi; Erik Engblom - erik.engblom@tyks.fi; Jukka Nikoskelainen - jukka.nikoskelainen@utu.fi; Pirkko Kotilainen* - pirkko.kotilainen@utu.fi

* Corresponding author

\section{Published: 17 April 2008}

BMC Infectious Diseases 2008, 8:49 doi:10.1 |86/147/-2334-8-49

This article is available from: http://www.biomedcentral.com/I47I-2334/8/49

(C) 2008 Heiro et al; licensee BioMed Central Ltd.

This is an Open Access article distributed under the terms of the Creative Commons Attribution License (http://creativecommons.org/licenses/by/2.0), which permits unrestricted use, distribution, and reproduction in any medium, provided the original work is properly cited.
Received: 17 September 2007

Accepted: 17 April 2008

\begin{abstract}
Background: Only a few previous studies have focused on the long-term prognosis of the patients with infective endocarditis (IE). Our purpose was to delineate factors potentially associated with the long-term outcome of IE, recurrences of IE and requirement for late valve surgery.

Methods: A total of 326 episodes of IE in 303 patients were treated during 1980-2004 in the Turku University Hospital. We evaluated the long-term outcome and requirement for late valve surgery for 243 of these episodes in 226 patients who survived longer than I year after the initial admission. Factors associated with recurrences were analysed both for the I-year survivors and for all 303 patients.
\end{abstract}

Results: The mean (SD) follow-up time for the I-year survivors was II.5 (7.3) years (range 25 days to 25.5 years). The overall survival was $95 \%, 82 \%, 66 \%, 51 \%$ and $45 \%$ at $2,5,10,15$ and 20 years. In age and sex adjusted multivariate analyses, significant predictors for long-term overall mortality were heart failure within 3 months of admission ( HR I.97, 95\% Cl I.27 to 3.06; $p=0.003$ ) and collagen disease $(\mathrm{HR} 2.54,95 \% \mathrm{Cl} I .25$ to $5.19 ; \mathrm{p}=0.010)$ or alcohol abuse $(\mathrm{HR} 2.39,95 \% \mathrm{Cl}$ 1.30 to $4.40 ; p=0.005$ ) as underlying conditions, while early surgery was significantly associated with lower overall mortality rates ( $\mathrm{HR} 0.3 \mathrm{I}, 95 \% \mathrm{Cl} 0.17$ to $0.58 ; \mathrm{p}<0.00 \mathrm{I})$. Heart failure was also significantly associated with the long-term cardiac mortality $(p=0.032)$. Of all 303 patients, 20 had more than I disease episode. Chronic dialysis $(p=0.002)$, intravenous drug use $(p=0.002)$ and diabetes $(p=0.015)$ were significant risk factors for recurrent episodes of IE, but when analysed separately for the I-year survivors, only chronic dialysis remained significant $(p=0.017)$. Recurrences and late valve surgery did not confer a poor prognosis.

Conclusion: Heart failure during the index episode of IE was the complication, which significantly predicted a poor long-term outcome. Patients who underwent surgery during the initial hospitalisation for IE faired significantly better than those who did not. 


\section{Background}

The short-term outcome of infective endocarditis (IE) has been examined in several previous studies from the 1990's and 2000's [1-4], whereas only a small number of studies have addressed the long-term prognosis of the patients with IE. Moreover, most of the studies focusing on the long-term prognosis have involved only certain subgroups of patients, e.g., those with late prosthetic valve IE [5], IE with perivalvular abscess [6], surgically treated IE associated with intravenous drug use (IVDU) [7], or native valve IE in non-addicts [8], as well as of those undergone surgery for defined indications, e.g. aortic valve IE [9], mitral valve IE [10], or native or prosthetic valve IE [11]. Instead, the long-term outcome of IE in large series of unselected patients with IE has been the focus of rather few studies [12-15].

We have previously analysed the short-term and 1-year clinical outcome of 303 patients with 326 episodes of IE treated in our hospital during the years 1980-2004 [16]. In the present study, we set out to analyse the long-term clinical outcome of 243 of these episodes in 226 patients who survived longer than 1 year after the initial admission for IE. Our purpose was to delineate the clinical characteristics of the patients during the index hospitalisation for IE, which might be predictive of the long-term outcome of IE. One important issue involved the impact of early surgery on the long-term survival of the patients. We also evaluated risk factors potentially associated with the development of recurrences of IE and the requirement for late valve surgery.

\section{Methods}

Between 1980 and 2004, 303 patients with 326 episodes of IE were treated in the Turku University Hospital, Turku, Finland. We evaluated the long-term outcome of 226 of these patients who survived longer than 1 year after the initial admission. The hospital is a 1000-bed teaching facility with a cardiothoracic surgical department, serving as a tertiary referral centre for the southwestern part of the country, and as a primary care facility for infectious diseases for a region of about 200.000 inhabitants.

For each patient, data on age, sex, underlying diseases, causative agents of IE, affected valves, predisposing cardiac conditions and echocardiographic findings, as well as the development of complications and the need for valve surgery were collected by us for our previous study focusing on the changes of the clinical characteristics of IE during the 25-year study period [19]. In addition, serum Creactive protein (CRP) values, erythrocyte sedimentation rates (ESR) and white blood cell (WBC) counts on admission were registered previously $[16,20]$, as were the results of the polymerase chain reaction analyses from the removed valve tissue for those patients who underwent surgery during 1994-2005 [21]. In the present study, these data were used to analyse the association between various patient and disease characteristics and the longterm outcome of the patients after an episode of IE. The survival and causes of death were assessed based on data obtained from the National Population Registry, in which all deaths and causes of deaths of the Finnish residents are registered. The patients were also analysed for factors associated with recurrent episodes of IE and with requirement for late valve surgery. Data regarding the recurrences and late valve surgery were obtained from the hospital records of the patients.

The follow-up period for the outcome was from the admission to death, or if alive, up to February 2006.

\section{Definitions}

Long-term outcome was defined as the outcome $>1$ year after the admission for the index episode of IE. Early surgery was defined as surgery during the index hospitalisation, and late surgery was defined as surgery $>1$ year after the initial admission. A recurrence was defined as a new episode of IE caused by a different microorganism or by a microorganism of the same genus or species of the previous episode of IE after a period of more than 6 months. A relapse was defined as a new episode of IE caused by a microorganism of the same genus and species within 6 months after discharge.

The study was approved by the Institutional Committee on human research.

\section{Statistical analysis}

Four different end-points were analysed in the study: long-term overall mortality, long-term cardiac mortality, late valve surgery, and recurrent IE. The associations between the clinical characteristics and end-points were studied separately using survival analysis. The cumulative percentages for survival during different time periods were estimated using the Kaplan-Meier technique. Differences in cumulative percentages between groups were tested using log-rank test. Data regarding the long-term overall outcome, cardiac mortality, and late valve surgery were analysed for the 1-years survivors, and data regarding the repeated episodes of IE both for the 1-year survivors and for all 303 patients.

Early surgery, late surgery and recurrent IE were analysed as time-dependent covariates applying Cox's regression models. Differences between groups were quantified by hazard ratios and ninety-five percent confidence intervals.

Multivariate analyses of end-points were carried out using the Cox regression model with early surgery as a timedependent covariate. Stepwise method was used for 
model selection. The results of multivariate analysis were adjusted for age and sex and differences between groups were quantified by hazard ratios and ninety-five percent confidence intervals. Except for the laboratory parameters and indications for surgery, all of the clinical characteristics presented in Table 1 were included in multivariate analyses.

P-values less than 0.05 were considered as statistically significant. Statistical computations were carried out using SAS $^{\circledast}$ release 9.1/2005.

\section{Results}

The mean (SD) follow-up time for the 303 patients with 326 episodes of IE treated between 1980-2004 was 12.2 (7.4) years (range 1.0 to 25.5 years). The median survival was 5.0 years for all patients, and the range of survival for those who died during the follow-up was 4 days to 23 years. The overall survival for all 303 patients was $75 \%$, $72 \%, 62 \%, 49 \%, 38 \%$ and $34 \%$ at $1,2,5,10,15$, and 20 years. We included in this study the 226 patients, who survived longer than 1 year after the initial admission for IE. These patients had altogether 243 episodes of IE, of which 155 were designated as definite IE and the rest as possible IE by the Duke diagnostic criteria [17]. A detailed diagnostic classification has been previously published by us for 142 of these episodes [18].

There were 174 episodes in men and 69 episodes in women. The mean age (SD) of the patients was 52.4 (17.1) years (range 18 to 87 years). The mean (SD) follow-up time for the l-year survivors was 11.5 (7.3) years (range 25 days to 25.5 years), and the $25 \%$ percentile of the follow-up time was 4.8 years and the $75 \%$ percentile of the follow-up time was 17.8 years. The median survival was 7.1 years, and the range of survival for those who died during the follow-up was 4 days to 22.3 years. Of these patients, 67 underwent in-hospital valve surgery and 72 were treated both surgically and conservatively within 3 months of the admission. The proportions of various clinical characteristics (e.g. causative agents of IE, affected valves, predisposing cardiac conditions, development of complications) are presented in Tables 1 and 2. A total of 94 patients died during the follow-up. The causes of death were: recurrent IE $(n=1)$, sequelae of IE $(n=27)$, coronary heart disease $(n=18)$, malignancy $(n=16)$, infection other than IE $(n=14)$, stroke $(n=6)$, other or unknown cause $(n=12)$. Of the 27 patients who died of sequelae of IE, the cause of death was established to be heart failure in 18 patients and sudden death due to arrhythmia in 9 patients.

\section{Long-term overall outcome}

Among the 1-year survivors, the long-term overall survival was $95 \%, 82 \%, 66 \%, 51 \%$, and $45 \%$ at $2,5,10,15$, and
20 years (Figure 1). The association between the survival and various clinical characteristics during the initial episode of IE is presented in Table 1 . In univariate analysis, an age $\geq 65$ years when contracting the disease was significantly associated with higher mortality, as was malignancy, collagen disease, chronic dialysis, or alcohol abuse as underlying conditions. Mortality was significantly higher for the patients who developed heart failure within 3 months of the initial admission than for those with no heart failure (Figure 2a). Significant differences in mortality were observed between the patients with different predisposing cardiac conditions, the mortality being highest for the patients with congenital heart disease and lowest for the patients with bicuspid aortic valve. Mortality was significantly lower for the patients with IVDU than for those with no IVDU. The long-term survival was significantly better for the patients who underwent early (inhospital) surgery than for those who did not (Figure 2b). Survival was significantly better for the patients who were treated both surgically and conservatively within 3 months than for those who were treated only conservatively. There were significant differences in survival between the patients who underwent surgery on different indications, the survival being lowest for those operated on for heart failure.

Data on the serum CRP value, ESR, WBC count, and serum creatinine value on admission was available in 205, 149,217 , and 218 episodes of endocarditis, respectively. Higher survival rates were significantly associated with ESR value $<50 \mathrm{~mm} / \mathrm{h}$, or serum creatinine value $<100$ $\mu \mathrm{mol} / \mathrm{l}$ on admission.

In age and sex adjusted multivariate analysis, significant predictors for mortality were heart failure within 3 months of admission (HR 1.97, 95\% CI 1.27 to 3.06; $\mathrm{p}=$ 0.003 ) and collagen disease (HR 2.54, 95\% CI 1.25 to 5.19; $\mathrm{p}=0.010$ ) or alcohol abuse (HR 2.39, 95\% CI 1.30 to $4.40 ; \mathrm{p}=0.005$ ) as underlying conditions. Early surgery was significantly associated with lower overall mortality rates (HR $0.31,95 \%$ CI 0.17 to 0.58 ; p < 0.001 ). Also when recurrent episodes of IE were excluded from the analyses, heart failure (HR 1.73, 95\% CI 1.10 to $2.72 ; \mathrm{p}=$ 0.018 ), collagen disease (HR 2.67, 95\% CI 1.30 to 5.49; p $=0.008$ ), and alcohol abuse (HR 2.80, 95\% CI 1.51 to $5.19 ; \mathrm{p}=0.001$ ) remained significant risk factors for mortality, and early surgery was significantly associated with lower overall mortality rates (HR $0.32,95 \%$ CI 0.17 to 0.59; $\mathrm{p}<0.001)$.

\section{Long-term cardiac mortality}

Among the 1-year survivors, the long-term cardiac mortality was $3 \%, 10 \%, 16 \%, 25 \%$, and $29 \%$ at $2,5,10,15$, and 20 years (Figure 1 ). In univariate analysis, cardiac mortality was significantly associated with an age $\geq 65$ years 
Table I: Association between characteristics of infective endocarditis (IE) and survival (global and in different subgroups) at 2, 5, 10, I5, and 20 years after the admission in 243 episodes of IE in 226 patients who survived over I year after the initial episode of IE

\begin{tabular}{|c|c|c|c|c|c|c|c|}
\hline & \multirow{2}{*}{$\begin{array}{l}\text { Number of IE episodes in patients } \\
\text { surviving I year }\end{array}$} & \multicolumn{5}{|c|}{ Survival (\%) at different points of follow-up } & \multirow[t]{2}{*}{$\mathrm{p}$ value } \\
\hline & & 2 years & 5 years & 10 years & 15 years & 20 years & \\
\hline Global survival & 243 & 95 & 82 & 66 & 51 & 45 & \\
\hline \multicolumn{8}{|l|}{ Gender } \\
\hline Male & 174 & 97 & 83 & 68 & 50 & 45 & 0.567 \\
\hline Female & 69 & 91 & 80 & 59 & 51 & 46 & \\
\hline \multicolumn{8}{|l|}{ Age } \\
\hline 18-64 years & 172 & 99 & 90 & 76 & 60 & 54 & $<0.001$ \\
\hline$\geq 65$ years & 71 & 87 & 65 & 38 & 25 & 25 & \\
\hline \multicolumn{8}{|l|}{ Affected valves } \\
\hline Aortic & 85 & 95 & 85 & 63 & 52 & 46 & $0.171 *$ \\
\hline Mitral valve & 77 & 95 & 80 & 58 & 40 & 40 & \\
\hline Tricuspid valve & 12 & 100 & 100 & 100 & NAt & NA & \\
\hline Two native valves & 17 & 100 & 100 & 91 & 76 & 76 & \\
\hline Prosthetic valve(s) & 52 & 94 & 74 & 67 & 52 & 43 & \\
\hline \multicolumn{8}{|l|}{ Causative agents of IE } \\
\hline Staphylococcus aureus & 53 & 98 & 86 & 77 & 57 & 57 & $0.183^{*}$ \\
\hline Coagulase-negative staphylococci & 22 & 86 & 58 & 41 & 41 & 41 & \\
\hline Viridans streptococci & 50 & 96 & 91 & 77 & 56 & 50 & \\
\hline Enterococcus faecalis & 18 & 83 & 83 & 67 & 28 & 28 & \\
\hline Streptococcus pneumoniae & 5 & 100 & 100 & 53 & 53 & 53 & \\
\hline Other & 22 & 95 & 91 & 66 & 60 & 30 & \\
\hline Negative & 73 & 99 & 78 & 61 & 46 & 46 & \\
\hline \multicolumn{8}{|l|}{ Predisposing cardiac condition } \\
\hline Acquired valvular disease & 49 & 90 & 70 & 53 & 41 & 36 & 0.019 \\
\hline Prosthetic valves & 55 & 95 & 75 & 66 & 52 & 43 & \\
\hline Bicuspid aortic valve & 26 & 100 & 100 & 94 & 81 & 81 & \\
\hline Mitral valve prolapse & 30 & 97 & 93 & 74 & 62 & 62 & \\
\hline Congenital heart disease & 8 & 100 & 100 & 33 & 33 & NA & \\
\hline No underlying cardiac condition & 75 & 97 & 83 & 63 & 39 & 39 & \\
\hline \multicolumn{8}{|l|}{ Echocardiogarphic findings } \\
\hline \multicolumn{8}{|l|}{ Major criteria } \\
\hline Yes & 158 & 96 & 85 & 68 & 53 & 49 & 0.089 \\
\hline No & 85 & 95 & 78 & 61 & 46 & 39 & \\
\hline Vegetation & & & & & & & 0.162 \\
\hline Yes & 139 & 95 & 85 & 68 & 52 & 49 & \\
\hline No & 104 & 96 & 80 & 62 & 49 & 41 & \\
\hline \multicolumn{8}{|l|}{ Underlying conditions } \\
\hline \multicolumn{8}{|l|}{ Diabetes } \\
\hline Yes & 21 & 95 & 95 & 77 & 58 & 29 & 0.307 \\
\hline No & 222 & 95 & 81 & 64 & 49 & 45 & \\
\hline \multicolumn{8}{|l|}{ Dialysis } \\
\hline Yes & 5 & 60 & 40 & NA & NA & NA & 0.018 \\
\hline No & 238 & 96 & 83 & 66 & 51 & 46 & \\
\hline \multicolumn{8}{|l|}{ Collagen disease } \\
\hline Yes & 14 & 93 & 68 & 24 & 24 & 24 & 0.026 \\
\hline No & 229 & 96 & 83 & 68 & 52 & 46 & \\
\hline \multicolumn{8}{|l|}{ Malignancy } \\
\hline Yes & 11 & 82 & 62 & 31 & NA & NA & 0.004 \\
\hline No & 232 & 96 & 83 & 67 & 53 & 47 & \\
\hline \multicolumn{8}{|l|}{ Intravenous drug use } \\
\hline Yes & 19 & 100 & 100 & NA & NA & NA & 0.049 \\
\hline No & 224 & 95 & 81 & 64 & 50 & 44 & \\
\hline \multicolumn{8}{|l|}{ Alcohol abuse } \\
\hline Yes & 22 & 91 & 67 & 47 & 35 & NA & 0.029 \\
\hline No & 221 & 96 & 84 & 68 & 53 & 47 & \\
\hline Heart failure $\dagger \dagger$ & & & & & & & 0.047 \\
\hline
\end{tabular}


Table I: Association between characteristics of infective endocarditis (IE) and survival (global and in different subgroups) at 2, 5, 10, 15, and 20 years after the admission in $\mathbf{2 4 3}$ episodes of IE in 226 patients who survived over I year after the initial episode of IE

\begin{tabular}{|c|c|c|c|c|c|c|c|}
\hline Yes & 108 & 93 & 75 & 55 & 46 & 44 & \\
\hline No & 135 & 98 & 89 & 75 & 55 & 46 & \\
\hline \multicolumn{8}{|l|}{ Neurological complications $\dagger \dagger$} \\
\hline Yes & 60 & 95 & 78 & 66 & 52 & 52 & 0.766 \\
\hline No & 183 & 96 & 84 & 65 & 50 & 43 & \\
\hline \multicolumn{8}{|l|}{ Peripheral embolit† } \\
\hline Yes & 69 & 97 & 83 & 60 & 50 & 50 & 0.570 \\
\hline No & 174 & 95 & 82 & 67 & 51 & 43 & \\
\hline \multicolumn{8}{|l|}{ Early surgery (in-hospital) } \\
\hline Yes & 67 & 99 & 89 & 82 & 76 & 73 & $<0.001$ \\
\hline No & 176 & 94 & 80 & 59 & 41 & 34 & \\
\hline \multicolumn{8}{|l|}{ Mode of treatment $\dagger \dagger$} \\
\hline Surgical & 72 & 99 & 90 & 82 & 74 & 70 & $<0.001$ \\
\hline Conservative & 171 & 94 & 79 & 59 & 41 & 33 & \\
\hline \multicolumn{8}{|l|}{$\begin{array}{l}\text { Indications for in-hospital } \\
\text { surgery }\end{array}$} \\
\hline Congestive heart failure & 35 & 97 & 85 & 72 & 61 & 55 & $0.002 *$ \\
\hline $\begin{array}{l}\text { Valvular regurgitation without } \\
\text { heart failure }\end{array}$ & 18 & 100 & 94 & 94 & 94 & 94 & \\
\hline $\begin{array}{l}\text { Dehiscence of prosthetic valve } \\
\text { without heart failure }\end{array}$ & 8 & 100 & 88 & 88 & 88 & 88 & \\
\hline Repeated emboli & 3 & 100 & 100 & 100 & 100 & 100 & \\
\hline Intractable infection & 3 & 100 & 100 & 100 & 100 & 100 & \\
\hline \multicolumn{8}{|l|}{ Erythrocyte sedimentation $\ddagger, \S$} \\
\hline$\geq 50 \mathrm{~mm} / \mathrm{h}$ & 75 & 93 & 76 & 55 & 40 & 34 & 0.018 \\
\hline$<50 \mathrm{~mm} / \mathrm{h}$ & 74 & 97 & 89 & 77 & 56 & 53 & \\
\hline \multicolumn{8}{|l|}{ White blood cell count $\ddagger$ §S } \\
\hline$\geq 10 \times 10^{9} / 1$ & 119 & 97 & 83 & 63 & 41 & 41 & 0.142 \\
\hline$<10 \times 10^{9} / 1$ & 98 & 94 & 82 & 67 & 61 & 53 & \\
\hline \multicolumn{8}{|l|}{ Serum C-reactive protein $\ddagger$, } \\
\hline$\geq 100 \mathrm{mg} / \mathrm{l}$ & 100 & 96 & 83 & 62 & 48 & 48 & 0.927 \\
\hline$<100 \mathrm{mg} / \mathrm{l}$ & 105 & 94 & 80 & 68 & 51 & 43 & \\
\hline Serum creatinine value $\neq \pi T$ & & & & & & & $<0.001$ \\
\hline$\geq 100 \mu \mathrm{mol} / \mathrm{l}$ & 76 & 95 & 77 & 53 & 27 & 14 & \\
\hline$<100 \mu \mathrm{mol} / \mathrm{l}$ & 142 & 97 & 87 & 71 & 61 & 59 & \\
\hline
\end{tabular}

$*_{p}$ values for overall group differences; $\dagger N A=$ non-applicable, the follow-up did not reach the time point for any patient of the group; $\nmid \dagger$ within 3

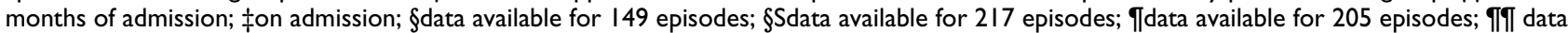
available for 218 episodes

when contracting the disease. There were significant differences in the long-term cardiac mortality between various causative agents of IE, the mortality being highest for Enterococcus faecalis, as well as between various predisposing cardiac conditions, the mortality being highest for acquired valvular disease. The long-term cardiac mortality was significantly lower for the patients who underwent early surgery than for those who did not. Mortality was significantly lower for the patients who were treated both surgically and conservatively within 3 months than for those who were treated only conservatively. The long-term cardiac mortality was significantly higher for the patients with serum creatinine value $\geq 100 \mu \mathrm{mol} / \mathrm{l}$ on admission than for those with lower serum creatinine values. The long-term cardiac mortality was significantly lower for the patients who had a major criterion or vegetation on echocardiography than for those who had no such findings on echocardiography.

In age and sex adjusted multivariate analysis, heart failure during 3 months of admission was significantly associated with high long-term cardiac mortality rates (HR 1.99, $95 \%$ CI 1.06 to $3.73 ; \mathrm{p}=0.032$ ), whereas the presence of a vegetation of echocardiography was significantly associated with low long-term cardiac mortality rates (HR 0.40, $95 \%$ CI 0.21 to $0.76 ; \mathrm{p}=0.005$ ). When recurrent episodes were excluded from the analyses, patients with heart failure had higher cardiac mortality rates, but the association did not reach statistical significance (HR 1.81, 95\% CI 0.95 to $3.44 ; \mathrm{p}=0.070$ ). Yet, vegetation remained as a factor significantly associated with lower cardiac mortality rates (HR $0.44,95 \% \mathrm{CI} 0.23$ to $0.84 ; \mathrm{p}=0.012$ ). 
Table 2: Association between characteristics of infective endocarditis (IE) and cardiac mortality at 2, 5, 10, 15, and 20 years after the admission in 243 episodes of IE in 226 patients who survived over I year after the initial episode of IE

\begin{tabular}{|c|c|c|c|c|c|c|c|}
\hline & \multirow{2}{*}{$\begin{array}{l}\text { Number of IE episodes in patients } \\
\text { surviving I year }\end{array}$} & \multicolumn{5}{|c|}{ Survival (\%) at different points of follow-up } & \multirow[t]{2}{*}{ p value } \\
\hline & & 2 years & 5 years & 10 years & 15 years & 20 years & \\
\hline Cardiac mortality & 243 & 3 & 10 & 16 & 25 & 29 & \\
\hline \multicolumn{8}{|l|}{ Gender } \\
\hline Male & 174 & 2 & 9 & 15 & 26 & 31 & 0.801 \\
\hline Female & 69 & 6 & 11 & 20 & 24 & 24 & \\
\hline \multicolumn{8}{|l|}{ Age } \\
\hline $18-64$ years & 172 & 1 & 5 & 11 & 22 & 26 & 0.002 \\
\hline$\geq 65$ years & 71 & 10 & 21 & 32 & 32 & 32 & \\
\hline \multicolumn{8}{|l|}{ Affected valves } \\
\hline Aortic & 85 & 4 & 9 & 18 & 24 & 29 & $0.416^{*}$ \\
\hline Mitral valve & 77 & 4 & 9 & 20 & 34 & 34 & \\
\hline Tricuspid valve & 12 & 0 & 0 & 0 & NA & NA & \\
\hline Two native valves & 17 & 0 & 0 & 0 & 17 & 17 & \\
\hline Prosthetic valve(s) & 52 & 4 & 17 & 17 & 24 & 29 & \\
\hline \multicolumn{8}{|l|}{ Causative agents of IE } \\
\hline Staphylococcus aureus & 53 & 2 & 4 & 4 & 4 & 4 & $0.032 *$ \\
\hline Coagulase-negative staphylococci & 22 & 10 & 20 & 30 & 30 & 30 & \\
\hline Viridans streptococci & 50 & 2 & 2 & 9 & 34 & 40 & \\
\hline Enterococcus faecalis & 18 & 17 & 17 & 25 & 63 & 63 & \\
\hline Streptococcus pneumoniae & 5 & 0 & 0 & 0 & 0 & 0 & \\
\hline Other & 22 & 0 & 0 & 16 & 16 & 28 & \\
\hline Negative & 73 & I & 17 & 22 & 25 & 25 & \\
\hline \multicolumn{8}{|l|}{ Predisposing cardiac condition } \\
\hline Acquired valvular disease & 49 & 8 & 19 & 29 & 41 & 41 & $0.015^{*}$ \\
\hline Prosthetic valves & 55 & 4 & 16 & 16 & 23 & 28 & \\
\hline Bicuspid aortic valve & 26 & 0 & 0 & 0 & 0 & 0 & \\
\hline Mitral valve prolapse & 30 & 3 & 3 & 15 & 29 & 29 & \\
\hline Congenital heart disease & 8 & 0 & 0 & 38 & 38 & NA & \\
\hline No underlying cardiac condition & 75 & I & 6 & 12 & 27 & 27 & \\
\hline \multicolumn{8}{|l|}{ Echocardiogarphic findings } \\
\hline \multicolumn{8}{|l|}{ Major criteria } \\
\hline Yes & 158 & 3 & 7 & 14 & 22 & 25 & 0.013 \\
\hline No & 85 & 4 & 15 & 22 & 32 & 36 & \\
\hline Vegetation & & & & & & & 0.007 \\
\hline Yes & 139 & 4 & 6 & 12 & 22 & 22 & \\
\hline No & 104 & 3 & 15 & 22 & 30 & 36 & \\
\hline \multicolumn{8}{|l|}{ Underlying conditions } \\
\hline \multicolumn{8}{|l|}{ Diabetes } \\
\hline Yes & 21 & 5 & 5 & 5 & 29 & 29 & 0.325 \\
\hline No & 222 & 3 & 10 & 18 & 26 & 30 & \\
\hline Dialysis & & & & & & & 0.340 \\
\hline Yes & 5 & 25 & 25 & NA & NA & NA & \\
\hline No & 238 & 3 & 9 & 16 & 25 & 29 & \\
\hline Collagen disease & & & & & & & 0.160 \\
\hline Yes & 14 & 7 & 24 & 49 & 49 & 49 & \\
\hline No & 229 & 3 & 9 & 15 & 24 & 28 & \\
\hline \multicolumn{8}{|l|}{ Malignancy } \\
\hline Yes & 11 & 10 & 10 & 40 & NA & NA & 0.383 \\
\hline No & 232 & 3 & 10 & 16 & 25 & 28 & \\
\hline \multicolumn{8}{|l|}{ Intravenous drug use } \\
\hline Yes & 19 & 0 & 0 & NA & NA & NA & 0.164 \\
\hline No & 224 & 4 & 10 & 17 & 26 & 30 & \\
\hline \multicolumn{8}{|l|}{ Alcohol abuse } \\
\hline Yes & 22 & 9 & 15 & 15 & 25 & NA & 0.660 \\
\hline No & 221 & 3 & 9 & 16 & 25 & 29 & \\
\hline
\end{tabular}


Table 2: Association between characteristics of infective endocarditis (IE) and cardiac mortality at 2, 5, 10, 15, and 20 years after the admission in 243 episodes of IE in 226 patients who survived over I year after the initial episode of IE (Continued)

\begin{tabular}{|c|c|c|c|c|c|c|c|}
\hline Yes & 108 & 6 & 15 & 23 & 28 & 31 & 0.110 \\
\hline No & 135 & 2 & 5 & 11 & 23 & 27 & \\
\hline \multicolumn{8}{|l|}{ Neurological complications $\nmid \dagger$} \\
\hline Yes & 60 & 3 & 11 & 18 & 27 & 27 & 0.930 \\
\hline No & 183 & 3 & 9 & 16 & 25 & 30 & \\
\hline Peripheral embolit† & & & & & & & 0.175 \\
\hline Yes & 69 & 3 & 8 & 14 & 20 & 20 & \\
\hline No & 174 & 3 & 10 & 17 & 27 & 32 & \\
\hline \multicolumn{8}{|l|}{ Early surgery (in-hospital) } \\
\hline Yes & 67 & 0 & 5 & 7 & 14 & 18 & 0.029 \\
\hline No & 176 & 5 & 12 & 20 & 30 & 34 & \\
\hline Mode of treatment $\nmid \dagger$ & & & & & & & 0.026 \\
\hline Surgical & 72 & 0 & 4 & 9 & 15 & 19 & \\
\hline Conservative & $|7|$ & 5 & 12 & 20 & 30 & 34 & \\
\hline \multicolumn{8}{|l|}{$\begin{array}{l}\text { Indications for in-hospital } \\
\text { surgery }\end{array}$} \\
\hline Congestive heart failure & 35 & 0 & 3 & 7 & 22 & 29 & $0.269 *$ \\
\hline $\begin{array}{l}\text { Valvular regurgitation without } \\
\text { heart failure }\end{array}$ & 18 & 0 & 6 & 6 & 6 & 6 & \\
\hline $\begin{array}{l}\text { Dehiscence of prosthetic valve } \\
\text { without heart failure }\end{array}$ & 8 & 0 & 13 & 13 & 13 & 13 & \\
\hline Repeated emboli & 3 & 0 & 0 & 0 & 0 & 0 & \\
\hline Intractable infection & 3 & 0 & 0 & 0 & 0 & 0 & \\
\hline \multicolumn{8}{|l|}{ Erythrocyte sedimentation $\ddagger$, } \\
\hline$\geq 50 \mathrm{~mm} / \mathrm{h}$ & 75 & 4 & 14 & 23 & 29 & 33 & 0.527 \\
\hline$<50 \mathrm{~mm} / \mathrm{h}$ & 74 & 1 & 6 & 13 & 30 & 34 & \\
\hline \multicolumn{8}{|l|}{ White blood cell count $\ddagger, \S S$} \\
\hline$\geq 10 \times 10^{9} / 1$ & 119 & 3 & 10 & 17 & 30 & 30 & 0.781 \\
\hline$<10 \times 10^{9} / 1$ & 98 & 4 & 9 & 17 & 24 & 31 & \\
\hline \multicolumn{8}{|l|}{ Serum C-reactive protein $\ddagger, \rrbracket$} \\
\hline$\geq 100 \mathrm{mg} / \mathrm{l}$ & 100 & 3 & 7 & 10 & 13 & 13 & 0.080 \\
\hline$<100 \mathrm{mg} / \mathrm{l}$ & 105 & 4 & 12 & 16 & 28 & 39 & \\
\hline \multicolumn{8}{|l|}{ Serum creatinine value $\ddagger, \llbracket P$} \\
\hline$\geq 100 \mu \mathrm{mol} / \mathrm{l}$ & 76 & 5 & 12 & 24 & 42 & 60 & 0.001 \\
\hline$<100 \mu \mathrm{mol} / \mathrm{l}$ & 142 & 1 & 7 & 13 & 18 & 18 & \\
\hline
\end{tabular}

$*_{p}$ values for overall group differences; $\nmid N A=$ non-applicable, the follow-up did not reach the time point for any patient of the group; $\dagger \nmid$ within 3

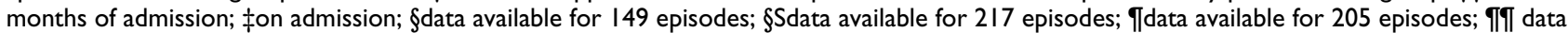
available for 218 episodes

\section{Late valve surgery}

Of all 326 episodes of IE in 303 patients treated between 1980 and 2004, valve surgery during the follow-up was performed in 126. Fifteen patients underwent 2 valve operations and 1 patient 3 valve operations. In 17 patients, the first valve operation was performed $>1$ year after the initial admission. Eight of them were operated on between 1 and 2 years, 5 patients between 2 and 5 years, 3 patients between 5 and 9 years, and 1 patient 16 years after the index episode of IE. In addition, 3 patients undergoing the first valve surgery during the initial hospitalisation underwent a reoperation more than 1 year (range 4 to 7 years) later. Thus, altogether 20 patients underwent late valve surgery. The indications for late valve surgery were: valvular regurgitation without heart failure $(n=15)$, dehiscence of prosthetic valve $(n=3)$, valvular stenosis ( $n$ $=1)$, and heart failure $(\mathrm{n}=1)$.
Patients who underwent late valve surgery had significantly lower overall mortality rates than those who did not (HR 0.36, 95\% CI 0.15 to 0.90 ; $\mathrm{p}=0.029$ ), but the cardiac mortality rates were not significantly different (HR $0.50,95 \%$ CI 0.15 to $1.62 ; \mathrm{p}=0.247$ ).

Based on univariate analyses, patients with neurological complications within 3 months of admission required late valve surgery significantly less common than those with no neurological complications $(\mathrm{p}=0.032)$. In age and sex adjusted multivariate analysis, no clinical factor during the initial hospitalisation was associated with the requirement of late valve surgery.

Patients with recurrences did not require late valve surgery more commonly that those with no recurrences (HR 1.04, $95 \%$ CI 0.24 to $4.63 ; \mathrm{p}=0.955$ ). 


\section{Cardiac Overall mortality (n)} mortality (n) 243

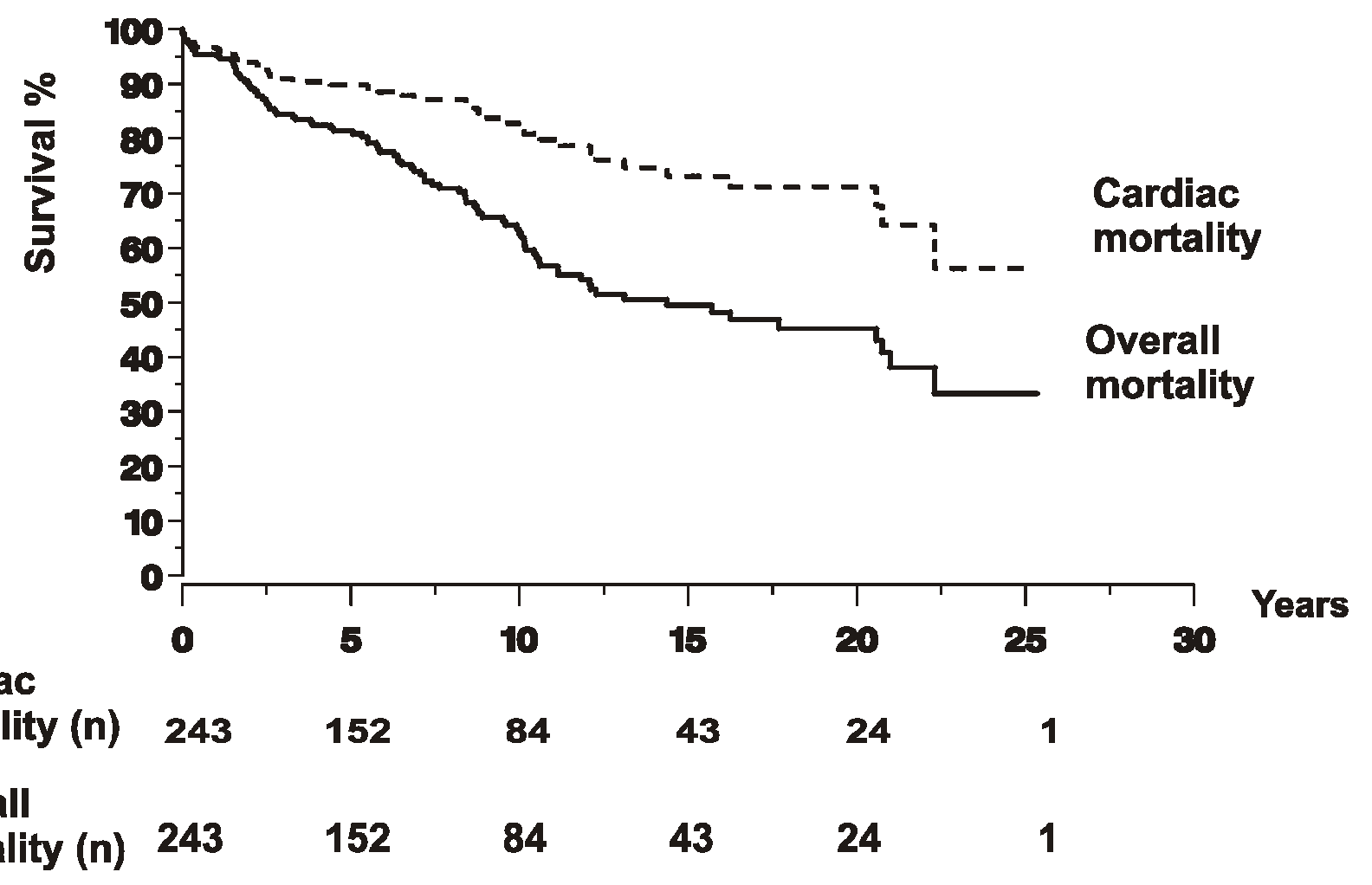

Figure I

Kaplan-Meier curves of the overall mortality and cardiac mortality for $\mathbf{2 4 3}$ episodes of infective endocarditis in 226 patients, who survived longer than I year after the initial episode. The numbers at different time points refer to the number of patients being followed up and at risk for event at the beginning of the time period. Zero on the time access indicates I year.

\section{Survival free of complications}

Among the 1-year survivors, survival free of complications (death, valve replacement, recurrence) after an episode of IE is shown in Figure 3.

\section{Repeated episodes of IE}

Of all 303 patients treated between 1980 and 2004, 20 had more than 1 episode of IE including 17 patients with 1 recurrence of IE, 2 patients with 2 recurrences of IE, and 1 patient with 1 recurrence and 1 relapse of IE. The relapse was a PVE caused by a Staphylococcus aureus strain genotypically identical with the strain causing native valve IE in the same patient 3 months earlier. Of the 23 repeated episodes of IE, prosthetic valves were involved in 16 .

\section{I-year survivors}

A total of 16 recurrences occurred among the 1-year survivors. In univariate analysis, the only factor during the index episode of IE significantly associated with recurrences in these patients was chronic dialysis $(\mathrm{p}<0.001)$. This association remained significant also in multivariate analysis (HR 20.73, 95\% CI 4.08 to 105.40 ; p < 0.001).
Patients with recurrent episodes of IE had significantly lower overall mortality rates than those with no recurrences (HR 0.09, 95\% CI 0.01 to $0.64 ; \mathrm{p}=0.017$ ).

\section{All patients}

In univariate analysis, the factors during the index episode of IE significantly associated with recurrences in all 303 patients with 23 recurrences were age $<65$ years $(\mathrm{p}=$ $0.016)$ and diabetes $(\mathrm{p}=0.022)$, chronic dialysis $(\mathrm{p}=$ $0.002)$ or IVDU $(\mathrm{p}<0.001)$ as underlying conditions. Also in age and sex adjusted multivariate analysis, chronic dialysis (HR 12.56, 95\% CI 2.54. to 62.24; $\mathrm{p}=0.002$ ), IVDU (HR 5.49, 95\% CI 1.84 to $16.43 ; \mathrm{p}=0.002$ ) and diabetes (HR 3.71, 95\% CI 1.30 to $10.62 ; \mathrm{p}=0.015$ ) remained significant. Patients with recurrent episodes of IE had significantly lower overall mortality rates than those with no recurrences (HR $0.05,95 \%$ CI 0.01 to 0.33 ; $\mathrm{p}=0.002)$.

\section{Discussion}

In this study, we analysed the long-term outcome of the patients treated for IE in a Finnish teaching hospital dur- 

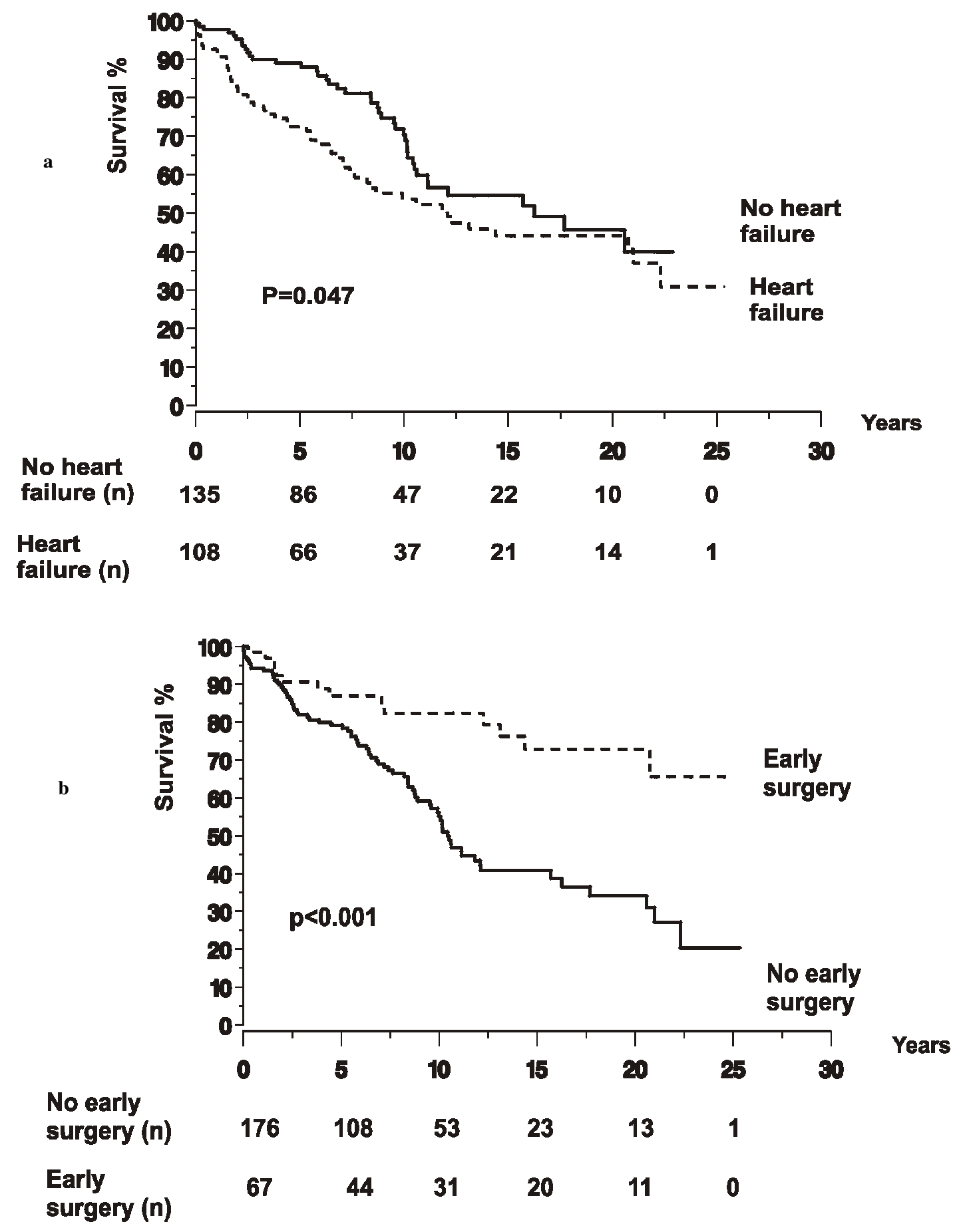

Figure 2

Long-term outcome was analysed for 243 episodes of infective endocarditis in 226 patients, who survived longer than I year after the initial episode. Kaplan-Meier curves of the overall survival for patients with and without heart failure during 3 months of admission (a), and for those undergoing and not undergoing early (in-hospital) surgery (b). The numbers at different time points refer to the number of patients being followed up and at risk for event at the beginning of the following time period. Zero on the time access indicates I year. 


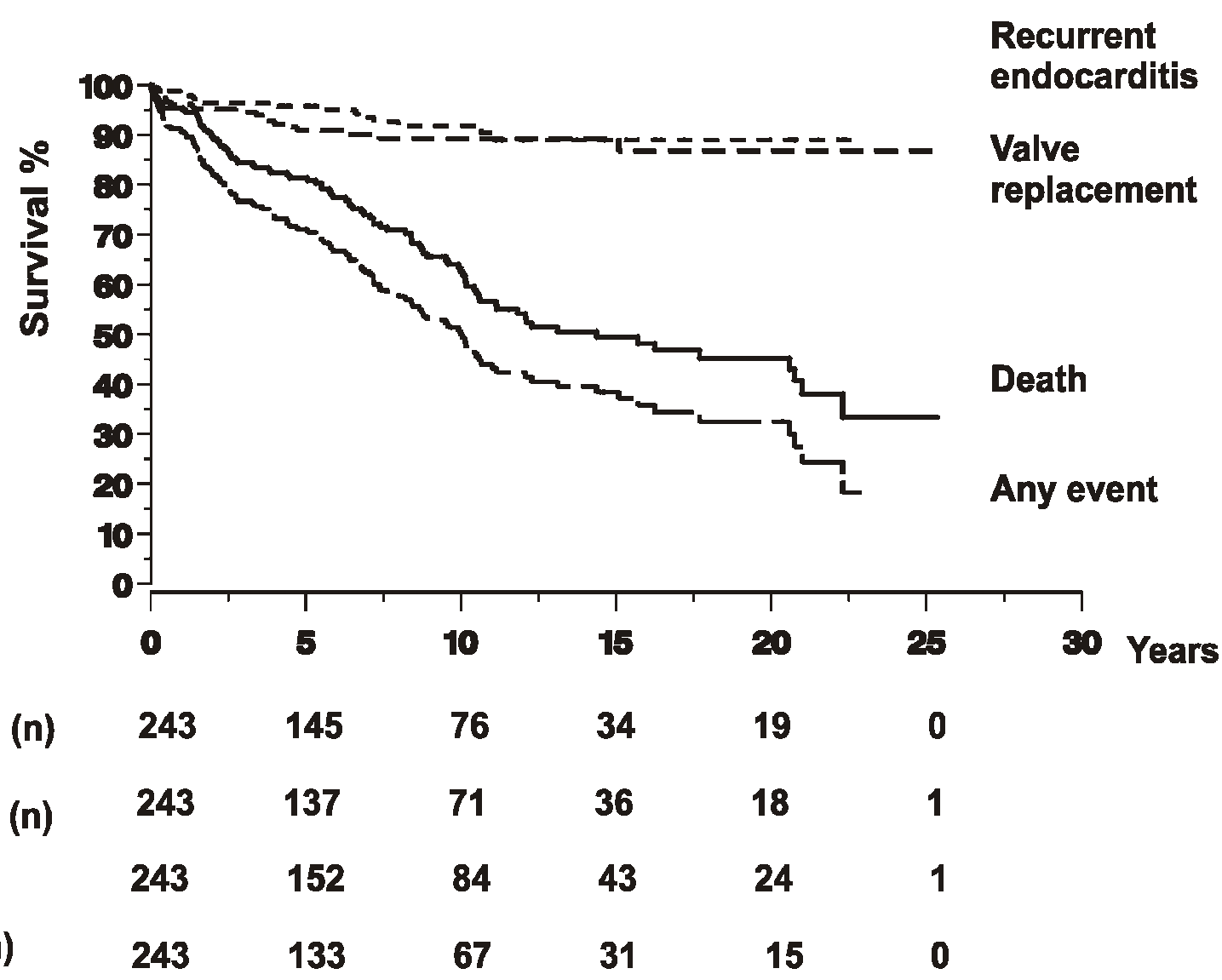

Figure 3

Kaplan-Meier curves of survival free of recurrent endocarditis, valve replacement, and death after an episode of infective endocarditis. The numbers at different time points refer to the number of patients being followed up and at risk for event at the beginning of the following time period. Zero on the time access indicates I year.

ing a period of 25 years. Among the 1-year survivors, the overall survival was $66 \%$ at 10 years, $51 \%$ at 15 years and $45 \%$ at 20 years. These figures are comparable with the results of previous studies $[12,15]$, although we are not aware of any earlier study in which the long-term survival has been analysed in an identical manner. Collectively, these data illustrate that despite major diagnostic and therapeutic advances, the mortality associated with IE remains high. At 10 years of follow-up, as many 51\% of our whole patient population and $34 \%$ of the 1 -year survivors had died. Admittedly, a few studies have been published reporting somewhat higher survival rates [13].

One of the main purposes of the present study was to define which clinical characteristics or complications of IE during the initial phase of endocarditis would be associated with an adverse long-term outcome of the patients. Consistent with previous studies $[12,14]$, older age at the time of contracting the disease predicted an adverse longterm outcome. Chronic dialysis as an underlying condi- tion predicted a poor overall long-term prognosis, as did alcohol abuse and collagen disease. In the patients with collagen disease, the severe nature of the underlying disease may have contributed to high mortality. Of all 9 patients with collagen disease who died during the follow-up, 3 needed chronic dialysis, 1 had nephrotic syndrome and in 3 patients, the cause of death was a malignancy. On the other hand, the survival was significantly better for the patients with IVDU than for those with no IVDU, but all of the patients with IVDU were young and most of them had a tricuspid valve disease with no mortality. Moreover, the follow-up time of these patients was short, since the first IVDU-associated case of IE occurred in our hospital in 1996.

Among the complications of IE, heart failure during the first 3 months of admission was significantly associated with long-term overall mortality and cardiac mortality. This corroborates other studies, which have found that heart failure is a major risk factor for long-term mortality 
[15]. Also among the surgically treated patients, the overall survival was lowest for those who were operated on for heart failure, underscoring the importance of heart failure as a poor long-term prognostic sign.

Neurological manifestations and peripheral emboli usually develop early in the course of endocarditis [16,22-24]. We have previously shown that in this patient population, the occurrence of neurological complications or peripheral emboli was significantly associated with short-term mortality as well as with mortality for up to 1 year of the admission [16]. In contrast, the results of the present study show that the long-term survival was practically similar for the patients with or without neurological manifestations or peripheral emboli during the acute phase of their illness (Table 1). This finding is not surprising, since once the patient has solved such an acute complication, it seems logical that it no longer influences the long-term prognosis.

In our series, early surgery was performed in $27.3 \%$ (89) of all 326 episodes [16]. Evaluation of the role of cardiac surgery on the prognosis of the patients with IE is a complex issue. Although early surgery is evidently life saving for certain groups of patients, it does not necessarily decrease the total mortality, since more and more critically ill patients are being treated surgically. This may be one of the reasons why the results regarding the role of early surgery as a prognostic factor have been conflicting. For example, when studying 280 patients treated in their unit between 1970 and 1982, Malquarty et al. [25] did not find any significant difference in the survival rate at 5 years between the surgical and non-surgical treatment groups. Neither did Tornos et al. [8] find any association between early surgery and a better survival rate during a 15-year follow-up among 140 patients hospitalised between 1975 and 1990. On the other hand, according to Bishara et al. [26], early surgical intenvention compared with medical therapy alone was associated with increased long-term survival rates in patients with IE treated between 1987 though 1996, primarily when IE was caused by $S$. aureus. Similarly, long-term survival was predicted by early surgical treatment in 212 patients with IE treated between 1980 and 1995 in a series described by Netzer at al. [15]. Moreover, Castillo et al. [13] have reported that a high early surgery rate was related to good long-term results in 138 cases of IE hospitalised between 1987 and 1997. Our results corroborate these findings: early surgery led to significantly lower overall and cardiac mortality rates in these 1-year survivors, although in multivariate analysis, the association was not significant regarding the long-term cardiac mortality. Thus, the results of the present study support the contention that a successful and correctly focused early valve surgery may decrease mortality due to IE. This could be accomplished by a careful selection of appropriate patients to be treated surgically.

The prognosis of the patients surviving the initial phase of endocarditis is considered to be due to 3 main factors: the development of heart failure, the risk of recurrences and the need for later valve replacement. In our patients, repeated episodes of IE were not common, as 20 (6.6\%) of all 303 patients had recurrences and only 1 patient $(0.3 \%)$ had a relapse. The rate of recurrences concurs with other published series, in which the rate of recurrences has varied between 3.9 and $16 \%[12,14,27-29]$, but the rate of relapses was here somewhat lower than the 1.1 to $3.3 \%$ relapse rate reported in earlier studies $[8,14,30]$. Chronic dialysis, diabetes and IVDU were shown to be risk factors for the development of recurrences when analysed for all 303 patients treated in our hospital between 1980 and 2004. IVDU has been shown to be a risk factor also in some other [29], but not all [14], previous studies. Although recurrent endocarditis is considered to be a risk factor for death [14], the development of a recurrent episode of IE did not confer a poor prognosis in our patients; in direct contrast, patients with recurrences had a better long-term overall outcome than those with no recurrences. At least a partial explanation for this could be that IVDU was a risk factor for the recurrences of IE. The patients with IVDU had a significantly lower mortality than those with no drug use, evidently due to the fact that they commonly had tricuspid valve IE with low mortality.

Late surgery was required in $17(7.0 \%)$ of the 243 episodes. None of the clinical parameters during the initial episode of IE were found to be associated with the requirement for late valve surgery. The requirement for late surgery was not increased even in the patients with recurrent episodes of IE. Also this could be partly explained by the positive association between the development of recurrences and IVDU.

Survival free of complications decreased with time. Although the estimate for 20 -year survival was $45 \%$, the estimate for 20-year survival free of complications, i.e. recurrent endocarditis or valve replacement, was only a little more than $30 \%$.

\section{Conclusion}

In our patients, heart failure within 3 months of the admission for the index episode of IE was the complication, which significantly predicted a poor long-term outcome. Patients who underwent surgery during the initial hospitalisation for IE faired significantly better than those who did not. Corroborating earlier findings, these results support the contention that a successful and correctly focused early valve surgery may decrease mortality due to IE. This could be accomplished by a careful selection of 
appropriate patients to be treated surgically. It must be admitted that the heterogeneity of the patient population included in this study may be one limitation when applying our results in the daily clinical practice. An analysis of long-term prognostic factors in some defined subgroups of our whole study population may provide further valuable information in the future.

\section{Competing interests}

The author(s) declare that they have no competing interests.

\section{Authors' contributions}

All of the authors contributed substantially to the study. MH collected the data. MH and PK designed the study and wrote the original version of the manuscript. $\mathrm{HH}, \mathrm{SH}, \mathrm{TS}$, $\mathrm{KM}, \mathrm{EE}$ and JN contributed to evaluation of data and provided critical comments for the manuscript. $\mathrm{HH}$ and $\mathrm{SH}$ performed the statistical analyses. All authors read and approved the final version of the manuscript.

\section{Acknowledgements}

We express our thanks to Ms. Leeni Nurmi for her help in collecting patient data for this study. This study was financially supported by a grant from the Foundation of the Turku University to M.H. and by grants from the Turku University Central Hospital Research Fund to M.H., J.N. and P. $\mathrm{K}$., but the funding body had no role in the study design, collection, analysis or interpretation of data, or in the decision to submit the manuscript for publication.

\section{References}

I. Netzer ROM, Zollinger E, Seiler C, Cerny A: Infective endocarditis: clinical spectrum, presentation and outcome. An analysis of 212 cases 1980-1995. Heart 2000, 84:25-30.

2. Cabell CH, Jollis JG, Peterson GE, Corey GR, Anderson DJ, Sexton DJ, Woods CW, Reller LB, Ryan T, Fowler VG: Changing patient characteristics and the effect on mortality in endocarditis. Arch Intern Med 2002, 162:90-94.

3. Wallace SM, Walton BI, Kharbanda RK, Hardy R, Wilson AP, Swanton $\mathrm{RH}$ : Mortality from infective endocarditis: clinical predictors of outcome. Heart 2002, 88:53-60.

4. Chu VH, Cabell CH, Benjamin DK, Kuniholm EF, Fowler VG, Engemann J, Sexton DJ, Corey GR, Wang A: Early predictors of in-hospital death in infective endocarditis. Circulation 2004 109: 1745-1749.

5. Tornos P, Almirante B, Olona M, Permanyer G, González T, Carballo J, Pahissa A, Soler-Soler J: Clinical outcome and long-term prognosis of late prosthetic valve endocarditis: a 20 -year experience. Clin Infect Dis 1997, 24:38I-386.

6. Castillo JC, Anguita MP, Ruiz M, Delgado M, Mesa D, Romo E, Arizón $J M$, Vallés $F$ : Clinical features and outcome of non-drug addicted patients with infective endocarditis and perivalvular abscess. J Heart Valve Dis 2005, I 4:80 I-805.

7. Carozza A, De Santo LS, Romano G, Della Corte A, Ursomando F, Scardone M, Caianiello G, Cotrufo M: Infective endocarditis in intravenous drug abusers: patterns of presentation and longterm outcomes of surgical treatment. J Heart Valve Dis 2006, 15:|25-|3|.

8. Tornos MP, Permanyer-Miralda G, Olona M, Gil M, Galve E, Almirante $B$, Soler-Soler J: Long-term complications of native valve infective endocarditis in non-addicts. A 15-year follow-up study. Ann Intern Med 1992, I I 7:567-572.

9. Langley SM, Alexiou C, Stafford HM, Dalrymple-Hay MIR, Haw MP, Livesey SA, Monro JL: Aortic valve replacement for endocarditis: determinants of early and late outcome. I Heart Valve Dis 2000, 9:697-704.
10. Alexiou C, Langley SM, Stafford H, Haw MP, Livesey SA, Monro JL: Surgical treatment of infective mitral valve endocarditis: predictors of early and late outcome. J Heart Valve Dis 2000, 9:327-334.

II. Grûnenfelder J, Akins CW, Hilgenberg AD, Vlahakes GJ, Torchiana DF, Madsen JC, MacGillivray TE: Long-term results and determinants of mortality after surgery for native and prosthetic valve endocarditis. J Heart Valve Dis 2001, 10:694-702.

12. Delahaye F, Ecochard R, de Gevigney G, Barjhoux C, Malquarti V, Saradarian W, Delaye J: The long term prognosis of infective endocarditis. Eur Heart J 1995, I6(Suppl B):48-53.

13. Castillo JC, Anguita MP, Ramírez A, Siles JR, Torres F, Mesa D, Franco $M$, Muòoz I, Concha M, Vallés F: Long term outcome of infective endocarditis in patients who were not drug addicts: a 10 year study. Heart 2000, 83:525-530.

14. Mansur AJ, Dal Bó CM, Fukushima JT, Issa VS, Grinberg M, Pomerantzeff PM: Relapses, recurrences, valve replacements, and mortality during the long-term follow- up after infective endocarditis. Am Heart J 200I, I 41:78-86.

15. Netzer ROM, Altwegg SC, Zollinger E, Täuber M, Carrel T, Seiler C: Infective endocarditis: determinants of long term outcome. Heart 2002, 88:6I-66.

16. Heiro M, Helenius H, Hurme S, Savunen T, Engblom E, Nikoskelainen J, Kotilainen P: Short-term and one-year outcome of infective endocarditis in adult patients treated in a Finnish teaching hospital during 1980-2004. BMC Infect Dis 2007, 7:17.

17. Durack DT, Lukes AS, Bright DK, the Duke Endocarditis Service : New criteria for diagnosis of infective endocarditis: utilization of specific echocardiographic findings. Am J Med 1994, 96:200-209.

18. Heiro M, Nikoskelainen J, Hartiala J], Saraste MK, Kotilainen PM: Diagnosis of infective endocarditis. Sensitivity of the Duke vs von Reyn criteria. Arch Intern Med 1998, 158:18-24.

19. Heiro M, Helenius H, Mäkilä S, Savunen T, Engblom E, Nikoskelainen J, Kotilainen P: Infective endocarditis in a Finnish teaching hospital: a study on 326 episodes treated during 1980-2004. Heart 2006, 92: | 457-| 462.

20. Heiro M, Helenius H, Sundell J, Koskinen P, Engblom E, Nikoskelainen J, Kotilainen P: Utility of serum C-reactive protein in assessing the outcome of infective endocarditis. Eur Heart / 2005, 26: $1873-188 \mid$.

21. Kotilainen P, Heiro M, Jalava J, Rantakokko V, Nikoskelainen J, Nikkari S, Rantakokko-Jalava K: Aetiological diagnosis of infective endocarditis by direct amplification of rRNA genes from surgically removed valve tissue. An II-year experience in a Finnish teachning hospital. Ann Med 2006, 38:263-273.

22. Hart RG, Foster JW, Luther MF, Kanter MC: Stroke in infective endocarditis. Stroke 1990, 21:695-700.

23. Røder BL, Wandall DA, Espersen F, Frimodt-Møller N, Skinhøj P, Rosdahl VT: Neurologic manifestations in Staphylococcus aureus endocarditis: a review of 260 bacteremic cases in nondrug addicts. Am J Med 1997, 102:379-386.

24. Heiro M, Nikoskelainen J, Engblom E, Kotilainen E, Marttila R, Kotilainen P: Neurologic manifestations of infective endocarditis. A 17-year experience in a teaching hospital in Finland. Arch Intern Med 2000, 160:278I-2787.

25. Malquarti V, Saradarian W, Etienne J, Milon H, Delahaye JP: Prognosis of native valve infective endocarditis: a review of 253 cases. Eur Heart ] 1 984: I I-20.

26. Bishara J, Leibovici L, Gartman-Israel D, Sagie A, Kazakov A, Miroshnik $E$, Ashkenazi $S$, Pitlik S: Long-term outcome of infective endocarditis: the impact of early surgical intervention. Clin Infect Dis 200I, 33:1636-1643.

27. Van der Meer JTM, Thompson J, Valkenburg HA, Michel MF: Epidemiology of bacterial endocarditis in the Netherlands. I. Patient characteristics. Arch Intern Med 1992, 152:1863-1868.

28. Hoen B, Selton-Suty C, Lacassin F, Etienne J, Briançon S, Leport C, Canton P: Infective endocarditis in patients with negative blood cultures: analysis of 88 cases from a one-year nationwide survey in France. Clin Infect Dis 1995, 20:50I-506.

29. Welton DE, Young JB, Gentry WO, Raizner AE, Alexander JK, Chahine RA, Miller RR: Recurrent infective endocarditis. Analysis of predisposing factors and clinical features. Am J Med 1979, 66:932-938.

30. Verheul HA, van den Brink RB, van Vreeland T, Moulijn AC, Düren $D R$, Dunning $A J$ : Effects of changes in management of active 
infective endocarditis on outcome in a 25 -year period. Am J Cardiol 1993, 72:682-687.

\section{Pre-publication history}

The pre-publication history for this paper can be accessed here:

http://www.biomedcentral.com/1471-2334/8/49/prepub

Publish with BioMed Central and every scientist can read your work free of charge

"BioMed Central will be the most significant development for disseminating the results of biomedical research in our lifetime. " Sir Paul Nurse, Cancer Research UK

Your research papers will be:

- available free of charge to the entire biomedical community

- peer reviewed and published immediately upon acceptance

- cited in PubMed and archived on PubMed Central

- yours - you keep the copyright

Submit your manuscript here:

http://www.biomedcentral.com/info/publishing_adv.asp 